\title{
Cardiac Imaging-Physiologic Assessment of Coronary Artery Lesion
}

\author{
Maddury Jyotsna ${ }^{1}$ \\ ${ }^{1}$ Nizam's Institute of Medical Sciences, Hyderabad, Telangana, India
}

Ind J Car Dis Wom 2020;5:65-75

\begin{abstract}
Address for correspondence Maddury Jyotsna, MD, DM, Nizam's Institute of Medical Sciences, Hyderabad, Telangana, 500082, India (e-mail: janaswamyjyotsna@gamil.com).
\end{abstract}
Abstract
Keywords
- fractional flow reserve
- coronary flow reserve
- instantaneous wave free ratio
- resting full cycle ratio
- coronary physiology

Thirty percent of angiographically significant coronary lesions may be functionally significant. Physiological assessment is essential to treat intermediate coronary lesions before taking the decision for percutaneous intervention. Even when coronary artery bypass is planned as treatment modality in triple-vessel coronary artery disease, the SYNTEX II trial has shown that functionally significant lesion treatment by bypass grafts improves the outcome of these patients. In this article, possible ways of estimating the physiologic assessment of coronary lesion, and the advantages and disadvantages of methods of estimating the physiologic assessment of coronary lesions is discussed.

\section{Introduction}

Even though the coronary angiogram is the gold standard test for the detection of the presence and severity of coronary artery disease, the physiological significance is better to treat a particular coronary lesion. The severity of coronary lesion only on angiogram may underestimate or overestimate. In addition, other than luminal narrowing, multiple factors also contribute to ischemia, like the length and serial lesions and the amount of viable myocardium. That is the reason why a similar degree of the lesion in two different patients differs in producing the severity of myocardial ischemia. ${ }^{1,2}$

There are noninvasive methods also for the assessment of the physiologic significance of coronary lesions, like stress echocardiogram, magnetic resonance imaging, and nuclear myocardial perfusion scan. However, none give lesion-specific data within the coronary artery. ${ }^{2}$ The fractional flow reserve (FFR) measurement was introduced in the 1980s. At present, the recommendation is to show the ischemia of lesion before doing percutaneous coronary intervention $(\mathrm{PCI}){ }^{3}$

\section{Coronary Circulation}

Epicardial coronaries serve a conduit artery function, whereas resistance arteries $(100-400 \mu \mathrm{m})$ and arterioles $(>100 \mu \mathrm{m})$ contribute to coronary resistance. Normal coronary blood flow at rest is $250 \mathrm{~mL} / \mathrm{min}$ and can increase up to five times during stress. The increase in oxygen demand during stress is met by increasing blood flow and dilatation of microcirculation (-Fig. 1). Myocardial ischemia results from epicardial coronary artery stenosis of $50 \%$ or microcirculatory dysfunction. To some extent, only coronary angiography (CAG) gives the anatomical severity of coronary artery disease (CAD); for physiological significance, we require different varieties of tests.

\section{Methods to Determine the Physiologic Assessment of Coronary Artery Lesion}

There are two methods to determine the physiologic assessment of coronary artery lesion: (1) invasive methods and (2) noninvasive methods.

\section{Invasive Methods}

The invasive method of estimating coronary lesions can be done along with coronary angiogram itself or at the time of planned PCI. There are different indices for the physiologic assessment of coronary artery lesion, invasively.

\section{Fractional Flow Reserve}

Fractional flow is derived by the ratio of the pressure distal to the lesion (Pd) to the pressure in the aorta (Pa). FFR is the ratio of the maximal achievable blood flow through the stenotic artery to the maximal normal flow ( - Fig. 2). So, maximal

(C)2020 Women in Cardiology and Related Sciences

License terms 10.1055/s-0040-1709960. 


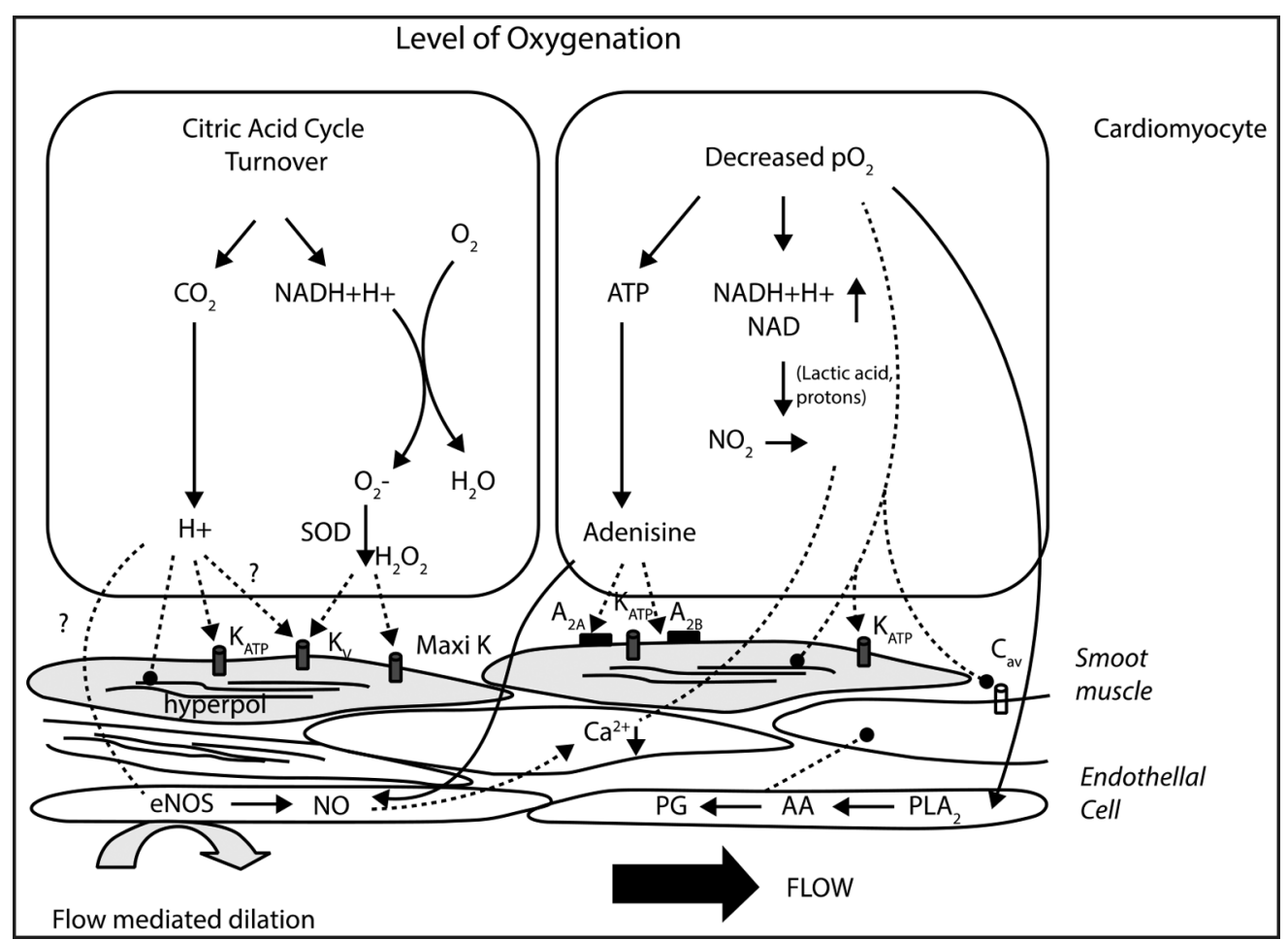

Fig. 1 Metabolic control of coronary circulation. Abbreviations: PLA2, phospholipase A2; AA, arachidonic acid; PG, prostaglandins.

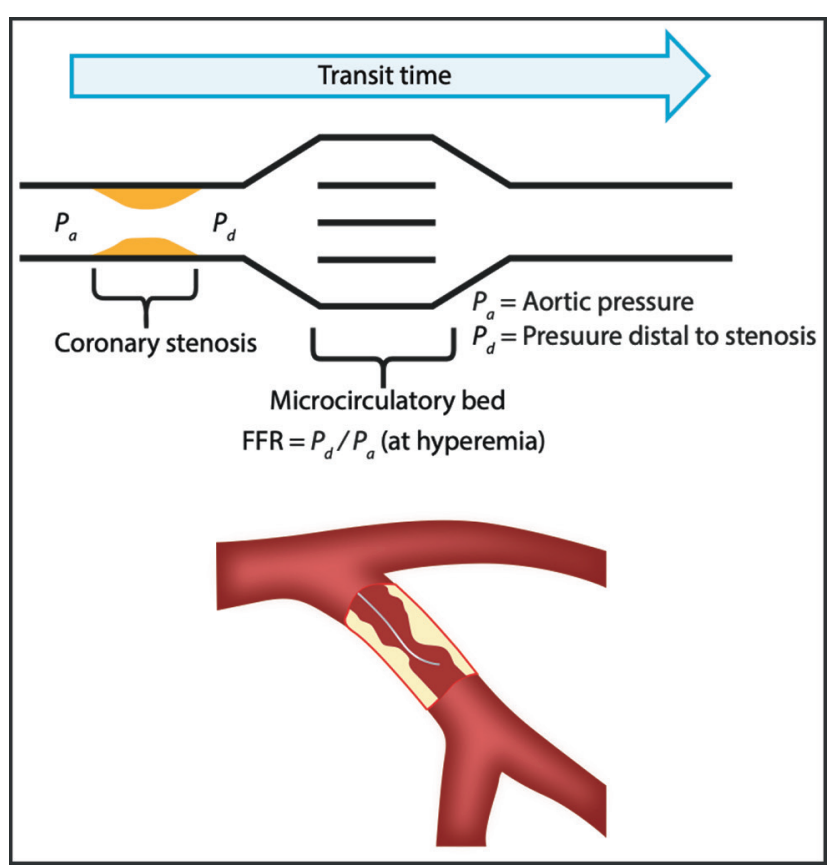

Fig. 2 Diagrammatic representation of FFR calculation.

vasodilation is mandatory for the calculation of the FFR. The original equation contains the venous pressure also in the calculation, but it is so low in normal conditions that is omitted. Heart failure and conditions associated with elevated venous pressures require consideration of the venous pressure also. ${ }^{4}$

\section{Physics of FFR}

On oxygen demand, autoregulation of the coronary circulation causes adequate coronary flow. When microvascular resistance is low there is linear relation between the pressure and flow ( - Fig. 3ab).

\section{Types of FFR Wires}

1. RADI FFR wire-Traditional FFR has hollow wire, sensor housing, and a tip. Sensor housing has a drift sensitive piezoelectric sensor, $10 \mathrm{~mm}$ away from the tip and there is abrupt transition proximal and distal to the sensor. Due to hollow wire body, torque control of the wire is poor.

2. COMET FFR wire-Due to Synergy's laser-cut high-torque sleeve there is improved deliverability and performance of the wire. It has optical pressure sensor which records accurate measurements and is prone to less pressure drift. Ashahi tip and coating facilitates better tip transition. In addition, it has free spin handle and wireless connection.

3. Dual-coil technology wire-It has Ashahi tip with actone with Synergy's laser-cut technology. This actone is a silicone coating on Ashahi ultrathin film with stainless steel core. The wire body is hydrophilic coated. This wire is highly torquable, flexible, and retains the tip shape for longer time.

4. Navvus microcatheter-RXi rapid exchange FFR system, featuring an ultrathin monorail pressure microcatheter, Navvus catheter, showed lesser FFR values than the traditional pressure wire, but this was not statistically significant.

5. iLab Polaris multimodality system-This is integrated with intravascular ultrasound (IVUS). This simplifies the procedure and decreases the procedure time. 


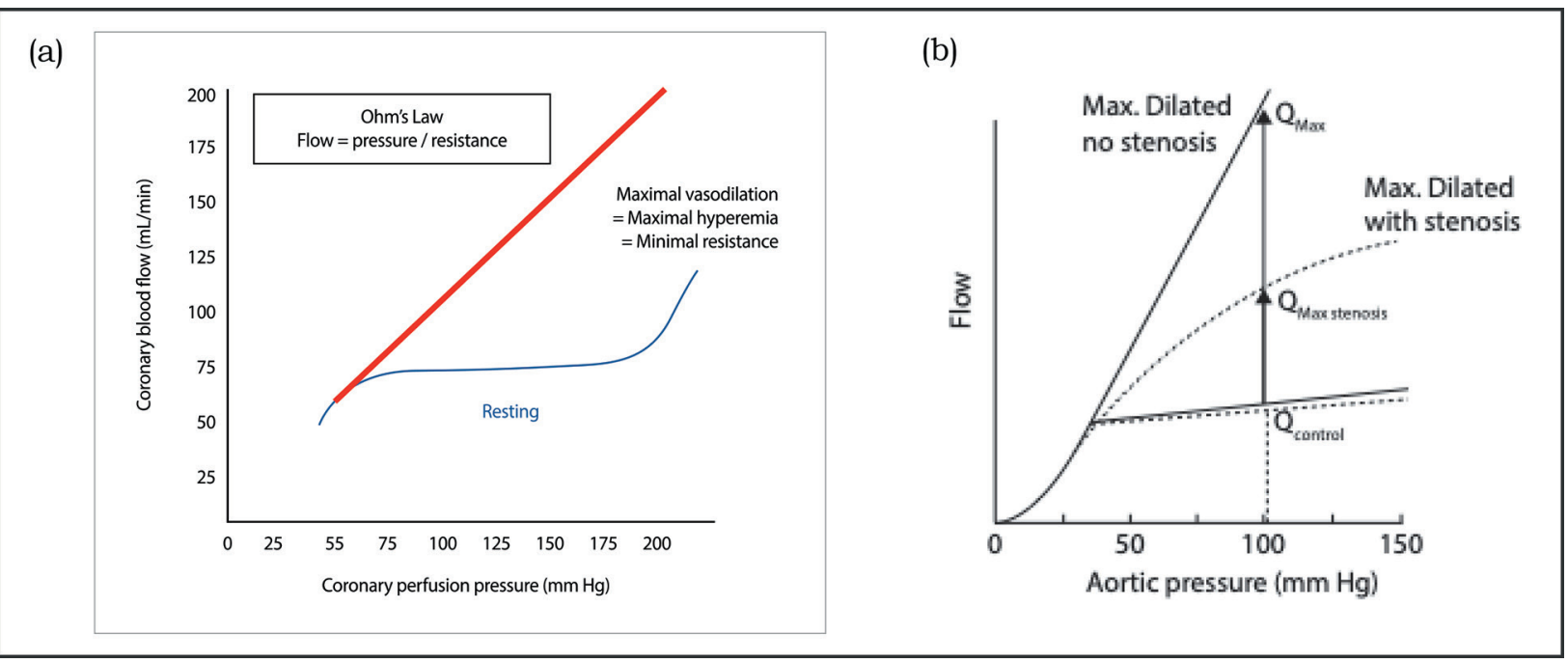

Fig. 3 (a) Pressure and flow response in normal artery, during resting and hyperemic conditions. (b) Comparison of pressure and flow during resting and hyperemic conditions of stenosed artery with normal artery.

\section{Preparation of the Patient}

If intravenous (IV) adenosine is planned for hyperemia, then large-caliber access in the femoral or cubital vein is required. Theophylline should be stopped 12 hours before FFR, but $\beta$-blockers need not be stopped. Caffeine intake within 1 hour of FFR should be avoided.

\section{Procedure}

Even though the FFR wire passes through the $6 \mathrm{~F}$ diagnostic catheter, a guide catheter (of at least $5 \mathrm{~F}$ ) without side holes is preferred for FFR due to its larger size and if FFR is positive, then PCI can be performed directly. Guide catheter with side holes may give false-positive FFR, as it creates a false gradient at the side hole and tip of the catheter. Also, maximal vasodilation by the adenosine may not be achieved as the drug partially goes to the aorta, not entirely into the coronary artery. It is better to avoid larger catheters and deep engagement. Coaxial engagement of the guide catheter is required. Anticoagulation should be given as per the PCI protocol. Nitroglycerin 100 to $200 \mu$ g should be given for epicardial vasodilatation.

For FFR measurement, proper zeroing of aortic pressure is required.

FFR is calculated by passing a specialized wire with a sensor distal to the coronary lesion. The catheter has to flush to remove the residual contrast, which can cause signal drift. Then equalization of the pressure sensor 1 to $2 \mathrm{~mm}$ distal to be tip of the guide catheter. Nonleaking thin introducer needle can be a leftover during FFR measurement, it is better to remove it otherwise. While wiring, minimal or no contrast should be used to prevent signal drift. The pressure transducer should be at least 20 to $30 \mathrm{~mm}$ distal to the lesion. The pressure distal to the lesion is represented as $\mathrm{Pd}$, and at the guide that is aorta as $\mathrm{Pa}$. Pd/Pa represents the basal gradient across the lesion. For a wire in a narrow vessel or severe tortuosity, the sensor may interact with the vessel wall and produce the artifacts. Pd/Pa ratio reflects FFR after maximum vasodilation. This means the important step in FFR calculation is the effective vasodilatation with pharmacological agents.

When there is a resting gradient $<0.80$, then measurement under hyperemia is not necessarily required to make a clinical decision. To achieve maximum hyperemia, it is better to give nitroglycerin to dilate epicardial coronaries first. IV adenosine $(140 \mu \mathrm{g} / \mathrm{kg} / \mathrm{min})$ is preferred over intracoronary injection, especially where there are tandom lesions are there and the wire is required to be pulled back. If FFR is in the borderline zone (0.75-0.8), then IV infusion may be increased to $180 \mu \mathrm{g} / \mathrm{kg} / \mathrm{min}$. Usually left main coronary artery (LMCA) requires $>200 \mu \mathrm{g}$ and $>100 \mu \mathrm{g}$ for right coronary artery (RCA) if adenosine is given intracoronary. With adenosine transient, atrioventricular blocks can happen. Another drug that can be used for hyperemia is regadenoson. It is a selective A $2 \mathrm{~A}$ receptor antagonist, and a single IV bolus injection of $400 \mu$ induces maximal hyperemia within the 30 seconds. It can produce a burning nonischemic chest pain. Papaverine $8 \mathrm{mg}$ for the right coronary artery and $12 \mathrm{mg}$ for the left coronary artery can also be used for the induction of hyperemia. This drug may cause transient QT prolongation, and very rarely ventricular tachycardia or torsade pointes. Nitroprusside $0.6 \mu \mathrm{g} / \mathrm{kg}$ in bolus is another alternative drug for hyperemia.

\section{Interpretation of FFR}

FFR value is the lowest $\mathrm{Pd} / \mathrm{Pa}$ ratio registered during the steady state. In the case of IV adenosine administrations, pressure values can fall to a minimum before reaching a steady state. These values should not be interpreted as FFR values. Ectopic beats or values measured under atrioventricular block/bradycardia can cause false-low FFR values, which must be excluded.

The normal value of FFR is 1 . FFR value 0.7 means that $70 \%$ of the blood flow without stenosis is only flowing through the stenosis. The pioneer work of Pijls et al ${ }^{5}$ suggested that FFR $<0.75$ is significant and requires revascularization. 
This is arrived at by comparing with sequential tests of exercise-stressed tests, thallium scintigraphy, and dobutamine-stress echocardiography. This cutoff value was tested in the DEFER trial ${ }^{6} 140 \mu \mathrm{g} / \mathrm{kg} / \mathrm{min}$ continuous IV infusion of adenosine is the gold standard for achieving maximal hyperemia. ${ }^{7}$ Even though IV adenosine is known to produce side effects like chest pain, atrioventricular blocks, and bronchospasm, all are of shorter duration and it is safe to use adenosine. A much simpler method of producing effective hyperemia is intracoronary 50 to $200 \mu$ of adenosine bolus. ${ }^{8}$ However, this route of administration is not useful in the FFR measurement in sequential lesions where pullback is required. Other than adenosine, drugs used for hyperemia are nicorandil, regadenoson, nitroprusside, and papaverine. The advantage of nicorandil is that it produces vasodilation of both macro- and microvascular systems. ${ }^{9,10}$

\section{Advantages of FFR}

FFR is reliable at all heart rates, blood pressure, and contractility. It a high-reproducibility and low intra-individual variability. This is independent of gender and CAD risk factors. It varies less with common doses of adenosine than does CFR.

\section{Limitations of FFR}

FFR has limited value in a patient with microvascular dysfunction, previous myocardial infarction, left ventricular hypertrophy, and diabetic microangiopathy as nonviable myocardium due to previous myocardial infarction does not vasodilate during hyperemia. So with similar coronary stenosis, a patient with nonviable myocardium will show high FFR.

\section{Controversies in FFR}

The controversies in FFR are as follows:

1. Acute coronary syndrome (ACS) - In ACS patients, significant vasoactive substances from the ruptured plaque and thrombus are generated, which preclude the proper hyperemic response for FFR estimation. During acute myocardial infarction (AMI), false-negative FFR may occur as there is microcirculatory defect which causes decrease in flow across the lesion leading to high FFR. However, an FFR of $<0.8$ is truly functionally significant. But, DANAMI3-PRIMULTI and Compare-acute trails in ACS situation showed 30\% approximate relative risk reduction of the composite of cardiac death or myocardial infarction using FFR-guided treatment.

2. Assessment of serial stenoses-In sequential stenotic lesions, the calculation of FFR is not simple. There will be an effect of distal lesion on the proximal lesion and vice versa. By keeping the transducer in between two lesions is also not reliable. Keeping the wire distal to both lesions shows the combined significance of both lesions. We can calculate accurately by measuring the coronary occlusive wedge pressure during hyperemia, which is not a practical method. ${ }^{11}$ Wire pull back during hyperemia has to be done first to see the step up at different lesions and determine the maximum pressure gradient producing lesion. To treat that lesion first and then reassess the FFR once again, to decide whether other lesion requires treatment or not.

\section{Artifacts and Pitfalls in FFR}

Pitfalls may be related to preparation, in measurement, or in the tracing interpretation. During preparation care should be taken to calibrate and equalize. During measurement attention should be paid to prevent drifting, wedging the catheter, and avoiding whipping of the pressure trace ( - Fig. 4), and ensuring that proper hyperemia has occurred. The drift is suspected when both pressure curves are identical in shape with proper dicrotic notch but shifted parallelly. On the contrary, when there is true gradient between the two pressure tracings then both curves do not look identical

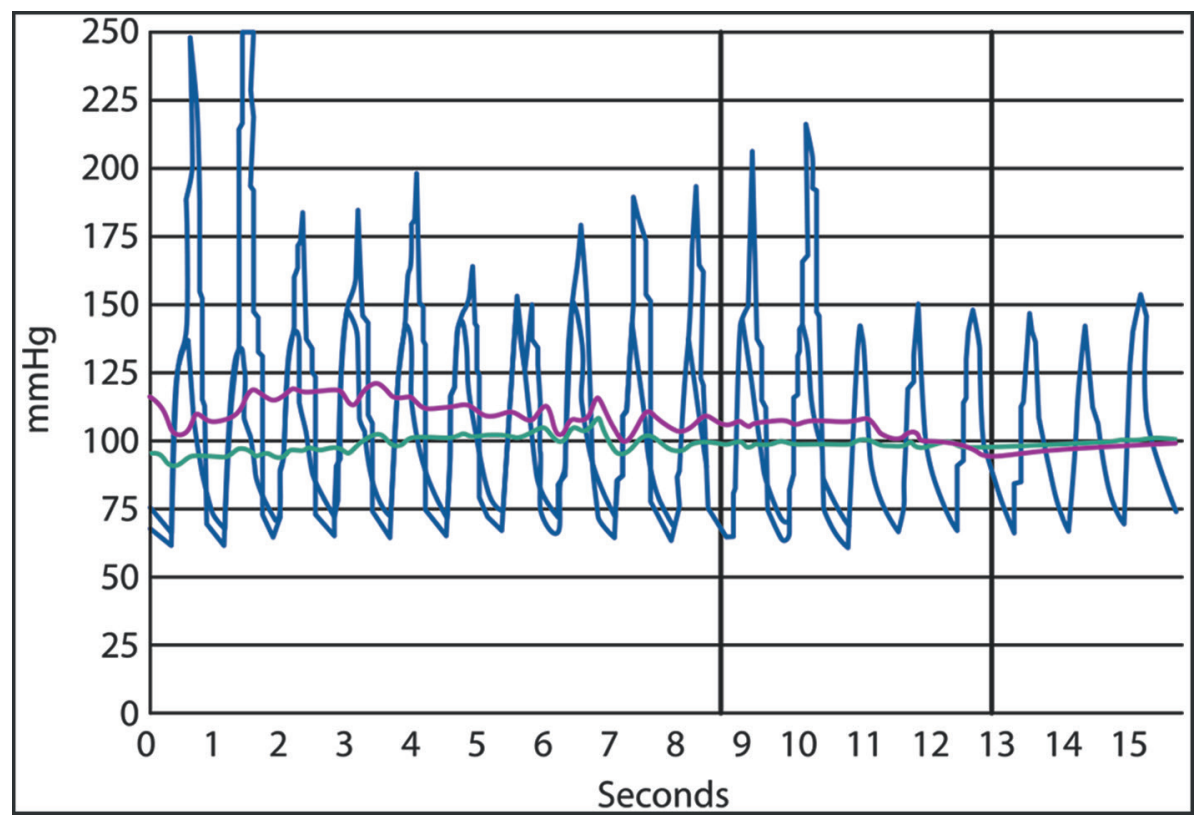

Fig. 4 Typical artifacts caused by mechanical interaction of the pressure sensor with vessel wall (whipping artifacts). 
and have different morphologies; they may show diastolic pressure difference without a dicrotic notch. If guide catheter is wedged, then calculated FFR is going to be high, as wedging produces the diastolic fall of the aortic pressure. So, the true diastolic gradient between the aortic and distal pressures is less. While interpreting the tracing the cursor should be adjusted to record the actual FFR, but not the lowest recorded FFR which may falsely be very low immediately after changing the pressure transducer from closed position to open position after adenosine injection for recording.

\section{Algorithm on How to Use FFR}

-Fig. 5 gives a flowchart to show the indications to the usage of FFR.

\section{Indications and Guidelines for FFR}

Concusses of multiple associations' recommendation of FFR is for the intermediate coronary lesions in chronic stable angina with Class Ila, level of evidence A.

\section{Conditions Where FFR Is Useful}

FFR is useful in the following conditions:
1. Pre-PCI

2. Post-PCI-Ideally, after PCI, 0.95 FFR is the best. Studies demonstrated that for up to 0.9 of FFR, there was no increase in cardiac events, but between 0.8 and 0.9 , the event rate increased.

3. Bifurcation lesion-In the case of bifurcation lesion PCI, revascularization of the side branch is not necessary if FFR is $>0.80$ in the side branch.

\section{FFR in Different Situations}

LMCA-Some precautions have to be taken while doing the FFR to LMCA. FFR measurement has to be done in downstream vessels without stenosis, optimally in both the left circumflex coronary artery and the left anterior descending coronary artery.

Continuous intravenous administration of adenosine is preferred than bolus intracoronary administration of adenosine \& withdrawal of the guide catheter from the ostium of LMCA, for FFR measurement.

Serial stenosis-It can only be evaluated jointly. The distally measured value represents the combined effect of both lesions. Values measured between two stenoses are

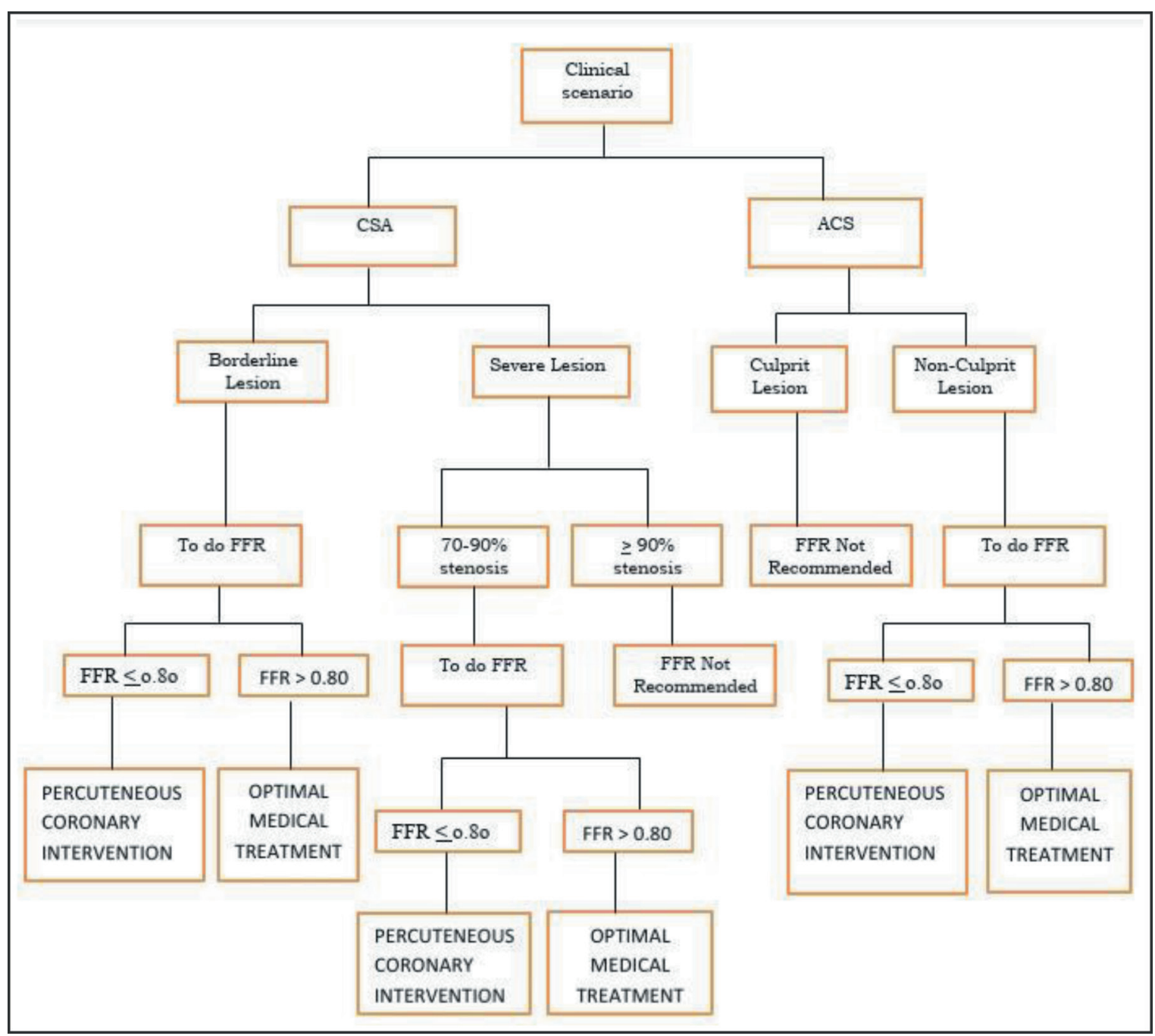

Fig. 5 Algorithm for FFR usage. 
unreliable. If FFR of the combined effect of two lesions is $<0.8$, then stent the tighter lesion and reassess the FFR once again.

\section{Why FFR was Not Popularized}

Even though it is a guideline recommended for revascularization, doing FFR was confined to a few cases as it requires additional time for hyperemia. However, now these other modes of physiological evaluation hyperemia induction are not required.

\section{Instantaneous Wave-Free Ratio}

The concept of instantaneous wave-free ratio (iFR) is to see the flow and pressure in the wave-free period of diastole (-Fig. 6). This corresponds to the beginning from $25 \%$ into diastole to 5 milliseconds before the end of diastole. The major advantage is that hyperemia is not required, and individual lesion severity can be assessed in serial lesions. With the co-registration software, iFR values at different segments of coronaries can be displayed by moving the cursor on the angiogram. In turn, iFR gives lesion-specific data and allows even the estimation of the improvement expected by

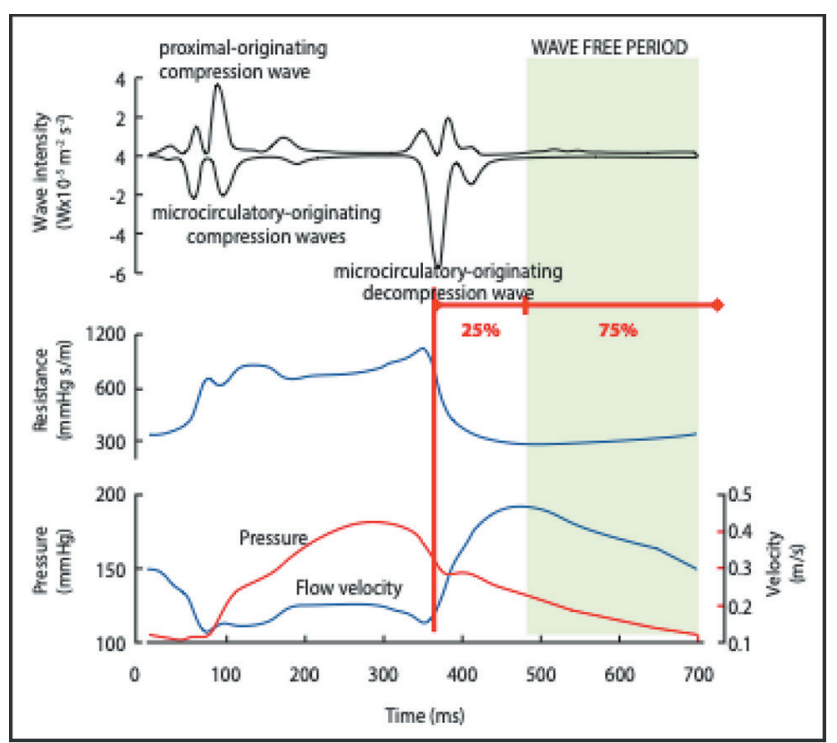

Fig. 6 Physics of iFR. treating the lesion and length of the stent required to get that improvement in the physiology of the lesion.

In the ADVISE study, the optimal cutoff value of iFR to predict FFR $<0.80$ was 0.83 with sensitivity, specificity, positive predictive value, and negative predictive values of $85 \%, 91 \%$, $91 \%$, and $85 \%$, respectively ${ }^{12}$ (-Fig. 7).

According to the ADVISE 2 and RESOLVE studies, there is 80 to $85 \%$ concordance between $\mathrm{iFR}$ and FFR when $\mathrm{iFR}=0.89 .{ }^{13,14}$

\section{Algorithm to Use iFR}

-Fig. 8 is a flowchart demonstrating the indications of iFR and the scenarios where iFR has to be done in addition to FFR.

\section{Resting Full-Cycle Ratio}

This measures the mean resting Pd/Pa over the entire cardiac cycle. It is simple and it does not require the detection of a specific point in the cardiac cycle.

\section{Coronary Flow Reserve}

The major limitation of both FFR and iFR is considering flow and pressure to be equivalent. Coronary flow reserve (CFR) directly measures the coronary flow ( $\mathbf{- F i g . 9}$ ). It is derived by the ratio of blood flow during maximal vasodilation divided by coronary blood flow during resting conditions. CFR is calculated by the thermodilution method or by Doppler flow velocity.

Normal CFR is 3.5 to 5 . Studies have demonstrated that CFR of $<2.7$ was a risk factor for CAD. The ischemic threshold of CFR is $<2$.

Another drawback of FFR and iFR is that these indices detect only epicardial arterial disease, which constitutes only $10 \%$ of coronary circulation, whereas CFR can detect even microvascular disease, which accounts for $90 \%$ of the coronary circulation.

FFR wire from the Radi company can be used for calculation of CFR as the transducer is even thermosensitive. In addition, FFR wire can be used as a workhouse wire.

rCFR is the maximal flow in a coronary artery with stenosis to maximal flow in a normal coronary artery without stenosis. The normal range of rCFR is 0.8 to 1.0 . The major limitations of this index are not applicable in multivessel

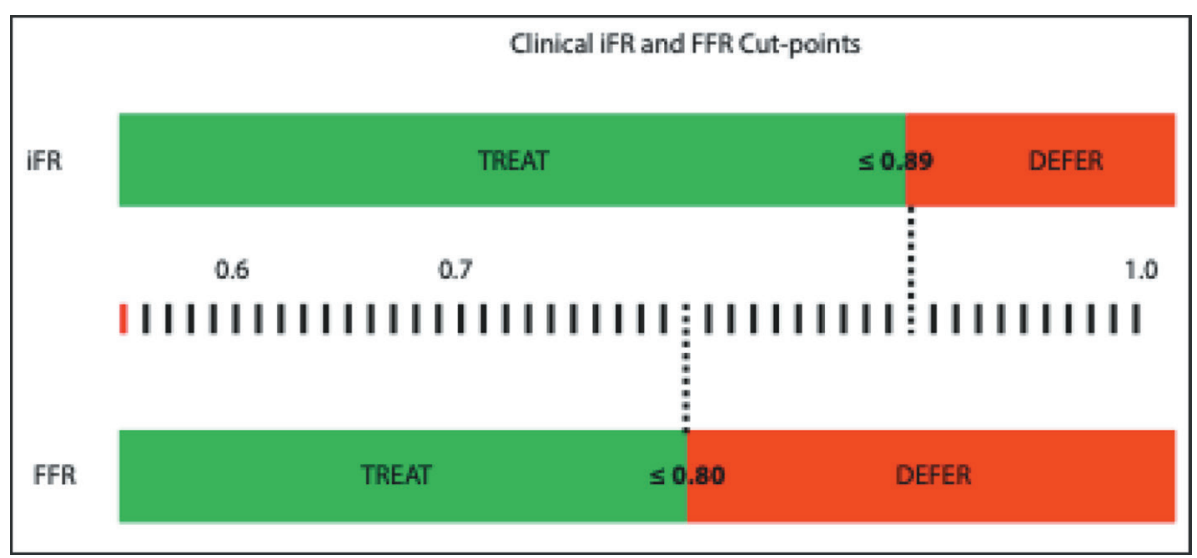

Fig. 7 Comparison of cutoff values of FFR and iFR. 


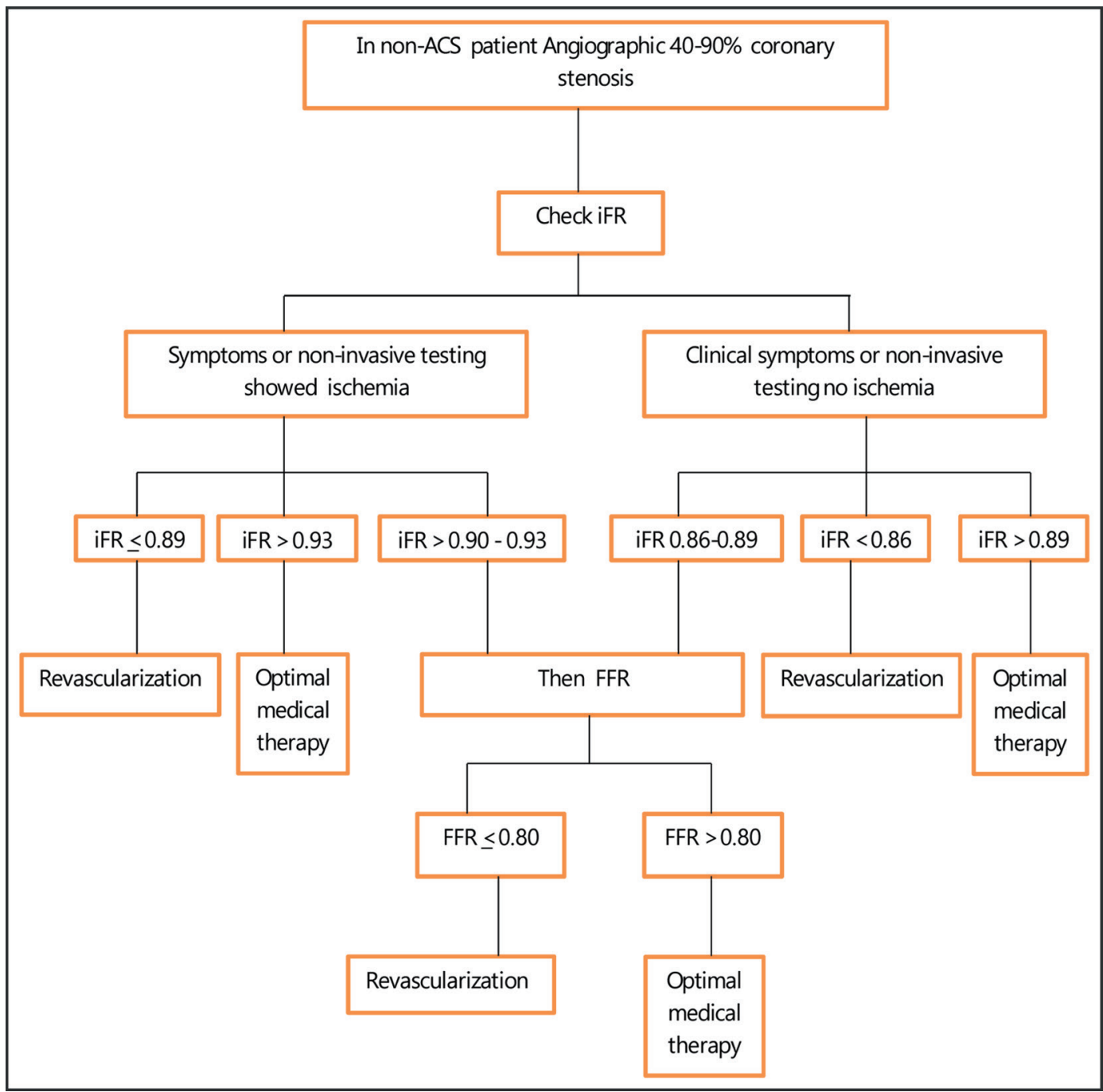

Fig. 8 Algorithm for iFR. Abbreviations: CSA, chronic stable angina; ACS, acute coronary syndrome.

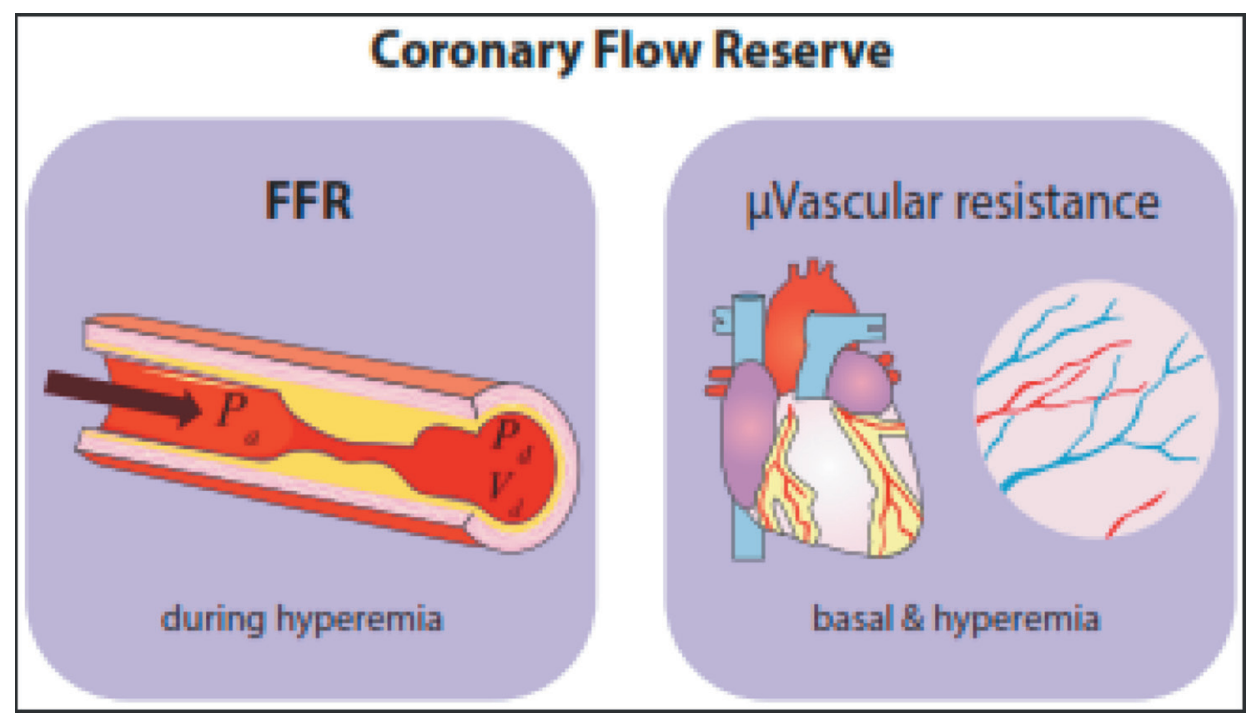

Fig. 9 Concept of coronary flow reserve (CFR). $F F R=P d / P a, B M R=P d / V d($ basal), $H M R=P d / V d$ (hyperemia). $C F R=1+F F R[(B M R / H M R)-1\}$. 
disease, in a patient with myocardial infarction, left regional ventricular dysfunction, or asymmetric hypertrophy. This is because the microvascular circulatory response is variable in the different regions of the myocardial bed, but rCFR assumes that microvascular circulatory response is uniform throughout the myocardial beds.

\section{Hyperemic Stenosis Resistance}

After primary $\mathrm{PCI}$, there are no measures to detect microcirculatory dysfunction, which is one of the major determinants of short- and long-term prognosis in AMI. Resistive reserve ratio ( $R R R$ ) expresses the microcirculation vasodilatory capacity. This is calculated by the ratio between basal and hyperemic microcirculatory resistance (-Fig. 10). This detects the suboptimal reperfusion. In one study, it was shown that RRR correlated better than CFR or index of myocardial resistance (IMR) in predicting the events rates at six months.

\section{Microvascular Assessment}

Among the deferred PCI patients of FAME 2, 14.6\% had persistence of angina and $9 \%$ had clinical events at 2-year

A

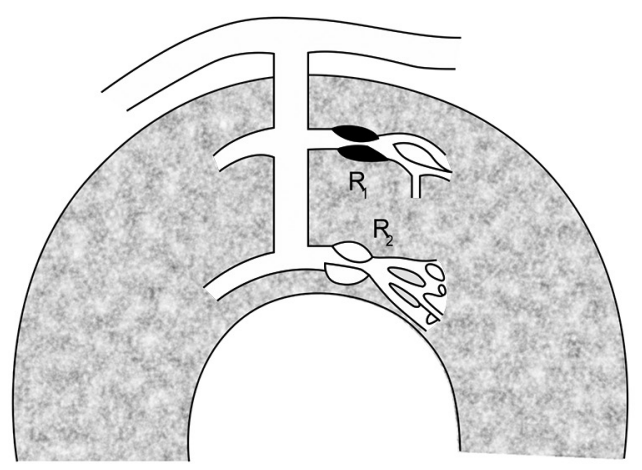

B

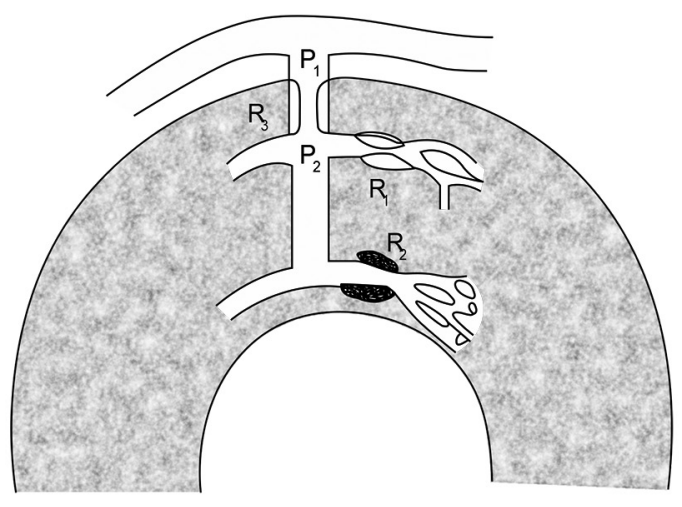

Fig. 10 Diagrams to show the cause of increased coronary resistance. (a) R2-at the arteriolar level. (b) R3-at the intramural prearteriole. $\mathrm{P} 1$ and $\mathrm{P} 2$ = pressures proximal and distal to the abnormal resistance, respectively; $\mathrm{R} 1$ = the normally responsive subepicardial arteriole. follow-up. ${ }^{11}$ This observation gives the information that the ischemia is not entirely contributed by the epicardial lesion. ${ }^{15}$ The coronary circulation contains three important components-conductive epicardial coronary arteries, arterioles, and capillaries. Ischemia in any one of these three components of coronary circulation produces myocardial ischemia.

The studies showed that CFR could be used to risk-stratify in high FFR patients. ${ }^{16-18}$ An index of microcirculatory resistance (IMR) can quantify the degree of microvascular dysfunction by using distal coronary pressure. IMR reflects more precisely the microvascular dysfunction than CFR, which is a combined assessment of the macro- and microcirculation.

In - Fig. 11 the FFR $_{\text {myo }}$ is explained. ${ }^{19,20}$ The ratio that represents the fraction of normal maximum flow that is preserved despite the presence of the stenosis is called FFR ${ }_{\text {myo }}$.

The myocardial blood flow depends on the basal pressure gradient across the lesion ( $\mathrm{FFR}_{\text {myo }}$ ), but not on the hyperemic pressure gradient. As shown in - Fig. 12, FFR ${ }_{\text {myo }}$ does not change even though the pressure change occurs, so FFR ${ }_{\text {myo }}$ is considered as lesion-specific index of stenosis severity. ${ }^{21}$

\section{Studies on Invasive Physiologic Assessment of Coronary Artery Lesion}

1. FFR Studies-FFR is useful in many intermediate coronary lesions including LMCA, ${ }^{22}$ except in tortuous heavily calcific lesions, where negotiation of relatively till stiff FFR wire is difficult. In - Table $\mathbf{1}$ important landmark trails of FFR are mentioned.

2. iFFR STUDIES-In - Table $\mathbf{2}$ iFR studies are mentioned.

\section{Noninvasive Methods}

FFR assessment can be done reliably by complete noninvasive method (e.g. CT scan) or by partial noninvasive method (e.g. FFR angio).

1. CT-derived FFR-Noninvasively FFR can be calculated using computational fluid dynamics (CFD) technology with CT (FFRCT). With cardiac computed tomography angiography (cCTA), the first three-dimensional (3D)

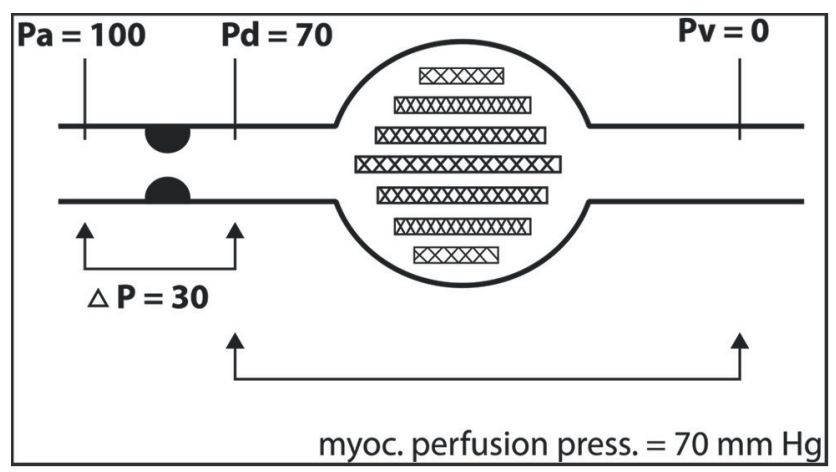

Fig. 11 Concept of FFR myo $_{\text {. }}$ 


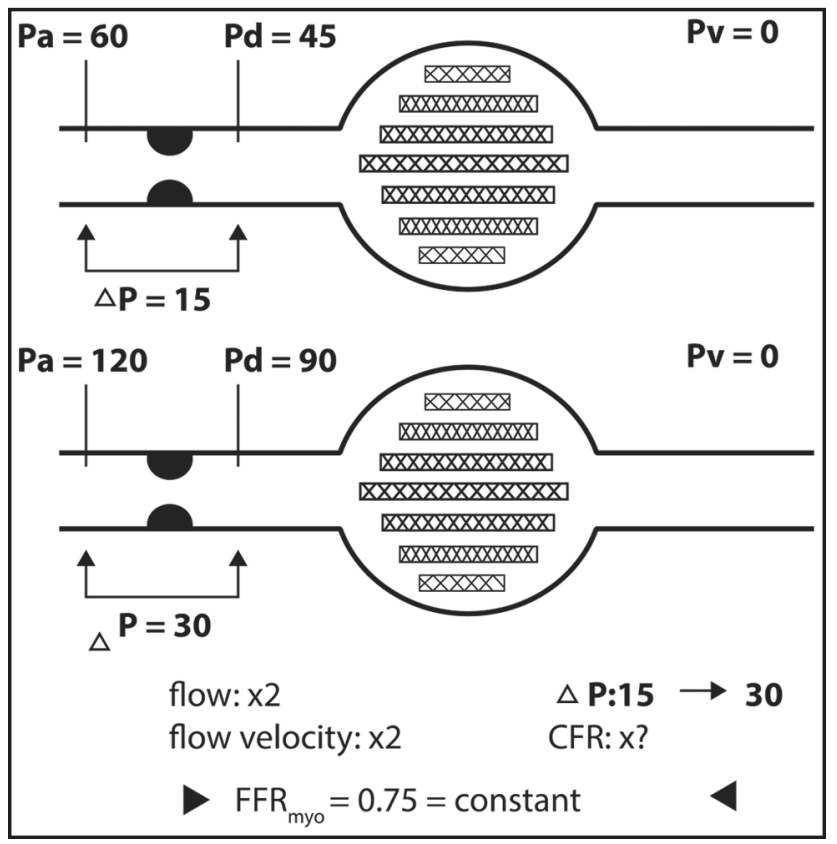

Fig. 12 Independence of FFR ${ }_{\text {myo }}$ from the loading conditions. anatomical coronary arterial model is constructed. Using allometric scaling law, total coronary flow is estimated from myocardial mass, from which the basal coronary outlet resistances are determined. With the morphometric law, the resistance of the downstream vessel to the vessel size at each outlet is determined. A mathematical model of hyperemic condition simulating adenosine-induced vasodilatation is derived. Then CFD analysis is performed based on the discretized model of patient-specific geometry and boundary conditions to numerically solve the governing equations of fluid dynamics, that is, Navier Stokes equations, as a Newtonian fluid. To detect the spatial distribution of FFRCT, the numerical solutions of coronary flow and pressure fields are computed.

2. FFRangio-The CathWorks FFRangio software device gives information of FFR noninvasively by deriving the flow dynamics from two conventional angiographic views of $25^{\circ}$ apart. The FFR values at each segment of angiogram are displayed when the cursor is moved on the $3 \mathrm{D}$ reconstructed angio. The major advantage of

Table 1 Landmark trails with FFR

\begin{tabular}{|c|c|c|c|}
\hline Study Name & Clinical presentation & FFR cutoff & Outcomes \\
\hline $\begin{array}{l}\text { DEFER }^{27} \\
2001\end{array}$ & intermediate stenosis in CSA & 0.75 & No benefit stenting a nonischemic stenosis \\
\hline $\begin{array}{l}\text { FAME }^{28} \\
2009\end{array}$ & Multivessel CAD & 0.80 & $\begin{array}{l}\text { FFR to all lesions in multivessel PCI with DES, } \\
\text { improves 1-y MACE }\end{array}$ \\
\hline $\begin{array}{l}\text { FAME } 2^{29} \\
2012\end{array}$ & $\begin{array}{l}\text { Stable CAD and hemodynamically } \\
\text { significant stenoses }\end{array}$ & 0.80 & $\begin{array}{l}\text { Even though angiographically severe lesion, } \\
\text { but FFR negative, then OMT showed excellent } \\
\text { outcomes }\end{array}$ \\
\hline $\begin{array}{l}\text { Muller et al }{ }^{30} \\
2011\end{array}$ & $\begin{array}{l}\text { Angiographically intermediate isolated } \\
\text { proximal LAD stenosis }\end{array}$ & 0.80 & $\begin{array}{l}\text { Angiographically equivalent lesion, but FFR } \\
\text { negative, then OMT showed excellent outcomes }\end{array}$ \\
\hline $\begin{array}{l}\text { Mayo Registry }{ }^{31} \\
2013\end{array}$ & $\begin{array}{l}\text { Patients undergoing PCl, excluding } \\
\text { STEMI or cardiogenic shock }\end{array}$ & $\begin{array}{l}<0.75 \rightarrow \mathrm{PCl} \\
0.75-0.80 \rightarrow \text { Operator } \\
\text { discretion }>0.8 \rightarrow \text { OMT }\end{array}$ & $\begin{array}{l}\text { FFR-guided treatment strategy is associated with } \\
\text { a favorable long-term outcome with decreased } \\
\text { MACE }\end{array}$ \\
\hline $\begin{array}{l}\text { Van Belle et al }{ }^{32} \\
2014\end{array}$ & Angiographically ambiguous lesion & 0.80 & $\begin{array}{l}\text { FFR during diagnostic angiography is safe } \\
\text { and reclassifies } 50 \% \text { of the patient into other } \\
\text { category of revascularization }\end{array}$ \\
\hline $\begin{array}{l}\text { RIPCORD } \\
2014\end{array}$ & Stable angina & 0.8 & $\begin{array}{l}\text { FFR guides for which coronary artery lesions to } \\
\text { be treated }\end{array}$ \\
\hline $\begin{array}{l}\text { DANAMI } 3 \\
\text { PRIMULTI } \\
2015\end{array}$ & $\begin{array}{l}\text { Patients with STEMI with multivessel } \\
\text { disease and undergone only PCI of an } \\
\text { infarct-related coronary artery }\end{array}$ & 0.80 & $\begin{array}{l}\text { FFR-guided complete staged revascularization, } \\
\text { reduces the risk of future events }\end{array}$ \\
\hline $\begin{array}{l}\text { Compare-Acute }{ }^{35} \\
2017\end{array}$ & $\begin{array}{l}\text { Patients with STEMI with multivessel } \\
\text { disease and undergone only PCI of an } \\
\text { infarct-related coronary artery }\end{array}$ & 0.80 & $\begin{array}{l}\text { FFR-guided complete revascularization in acute } \\
\text { condition, reduces the MACE }\end{array}$ \\
\hline $\begin{array}{l}\text { IRIS-FFR }{ }^{36} \\
2017\end{array}$ & $\begin{array}{l}\text { Patients with at least one coronary } \\
\text { lesion }\end{array}$ & 0.75 & $\begin{array}{l}\text { The risk of MACE was not significantly different } \\
\text { between deferred and revascularized lesions } \\
\text { depending on FFR cutoff value of } 0.75\end{array}$ \\
\hline FORZA $^{37}$ & $\begin{array}{l}\text { In patients with angiographically } \\
\text { intermediate coronary lesions (AICL), } \\
\text { FFR vs. OCT }\end{array}$ & $\mathrm{FFR} \leq 0.80$ & $\begin{array}{l}\text { The two tests offer different benefits, with OCT } \\
\text { holding a slight edge }\end{array}$ \\
\hline
\end{tabular}

Note: SYNTEX II, ongoing; FAME 3, ongoing, J, confirmed, ${ }^{38}$ PRIME FFR. ${ }^{39}$ 
Table 2 Important iFR studies

\begin{tabular}{|c|c|c|c|}
\hline Study name & Clinical presentation & iFR cutoff & Outcomes \\
\hline DEFINE $\mathrm{PCl}^{40}$ & $\begin{array}{l}\text { Pts with stable or unstable } \\
\text { angina with either multivessel or } \\
\text { multilesion coronary artery disease } \\
\text { with an abnormal baseline iFR }\end{array}$ & $\mathrm{iFR} \leq 0.89$ & $\begin{array}{l}\text { Residual ischemia after angiographically successful } \\
\text { PCI was seen in } 24.0 \% \text { pts by iFR estimation }(0.84 \pm \\
0.06)\end{array}$ \\
\hline ADVISE II ${ }^{13}$ & $\begin{array}{l}\text { To assess the clinical value of iFR } \\
\text { to characterize, coronary stenosis } \\
\text { severity as determined with FFR }\end{array}$ & iFR 0.89 & Minimum iFR of 0.89 has FFR agreement is $\geq 80 \%$ \\
\hline RESOLVE $^{14}$ & FFR and iFR in CSA patients & & $\begin{array}{l}\text { Endothelial dysfunction (by EndoPAT), plaque } \\
\text { superficial irregularities (by OCT), and gene } \\
\text { polymorphisms (in ENOS and HO-1) can be different } \\
\text { in patients with discrepancy between FFR and iFR }\end{array}$ \\
\hline DEFINE-FLAIR ${ }^{41}$ & $\operatorname{iFR}(n=1,242)$ vs. FFR $(n=1,250)$ & iFR value was $\leq 0.89$ & $\begin{array}{l}\text { The primary outcome, incidence of all-cause death, } \\
\text { MI, or unplanned revascularization at } 12 \text { months, } \\
\text { occurred in } 6.8 \% \text { of the iFR group vs. } 7.0 \% \text { of the FFR } \\
\text { group ( } p<0.001 \text { for noninferiority) }\end{array}$ \\
\hline SWEDEHEART ${ }^{42}$ & $\begin{array}{l}\text { Patients with CSA or ACS } \\
\text { randomized to treatment guided by } \\
\text { iFR or FFR }\end{array}$ & iFR value was $\leq 0.89$ & $\begin{array}{l}\text { An iFR-guided revascularization strategy was } \\
\text { noninferior to an FFR-guided revascularization } \\
\text { strategy for MACE at one year }\end{array}$ \\
\hline
\end{tabular}

Abbreviations: ADVISE II, ADenosine Vasodilator Independent Stenosis Evaluation II; DEFINE-FLAIR, Functional Lesion Assessment of Intermediate Stenosis to Guide Revascularisation; DEFINE PCI, Physiologic Assessment of Coronary Stenosis Following PCl; RESOLVE, multicenter core laboratory comparison of the instantaneous wave-free ratio and resting Pd/Pa with fractional flow reserve; SWEDEHEART, coronary angiographic findings and outcomes in patients with sudden cardiac arrest without ST-elevation myocardial infarction.

FFRangio is that it does not require a wire, contrast, or vasodilator, and can be done on proper images of angiogram only.

\section{Studies on CT-Derived FFR}

1. DISCOVER-FLOW (Diagnosis of Ischemia-Causing Stenoses Obtained via Noninvasive Fractional Flow Reserve) virtual PCI technology-Diagnostic results from this noninvasive version of FFR correlated well with conventional FFR $(\mathrm{R}=0.72 ; p<0.0001)$, with a slight underestimation $(0.022 \pm 0.116 ; p=0.016)$ at the per-vessel level but no difference on a per-patient basis $(p=0.131)$. Use of CT-derived FFR yielded a false-positive rate of $11.3 \%$ and a false-negative rate of $4.4 \% .^{23}$

2. DeFACTO-In CSA patients, FFRCT improved the diagnostic accuracy in detecting the severity of coronary lesion. But a major drawback of this study is that it did not achieve the prespecified primary goals. ${ }^{24}$

3. NXT trail-In this study FFRCT was compared with invasive FFR and showed high diagnostic accuracy for CAD detection. Also, FFRCT increased the specificity for CAD detection when compared with only anatomical assessment of coronary anatomy by CTA. ${ }^{25}$

4. PLATFORM-In CSA patients, both groups (invasive coronary angiography vs. CTA with selective FFRCT) showed same clinical outcomes and quality of life at 1 -year follow-up. ${ }^{26}$

\section{Conflict of Interest}

None declared.

\section{References}

1 Bhatt DL. Fractional flow reserve measurement for the physiological assessment of coronary artery stenosis severity. JAMA 2018;320(12):1275-1276

2 Ali N, Patel PA, Malkin CJ. Assessment of coronary physiology-the evidence and implications. Clin Med (Lond) 2019;19(5):364-368

3 Robertson KE, Hennigan B, Berry C, Oldroyd KG. Physiological assessment of coronary lesion severity: fractional flow reserve versus nonhyperaemic indices. Coron Artery Dis 2015;26(Suppl 1) :e8-e14

4 Hwang D, Lee JM, Koo B-K. Physiologic assessment of coronary artery disease: focus on fractional flow reserve. Korean J Radiol 2016;17(3):307-320

5 Pijls NH, De Bruyne B, Peels K, et al. Measurement of fractional flow reserve to assess the functional severity of coronaryartery stenoses. N Engl J Med 1996;334(26):1703-1708

6 Bech GJ, De Bruyne B, Pijls NH, et al. Fractional flow reserve to determine the appropriateness of angioplasty in moderate coronary stenosis: a randomized trial. Circulation 2001;103(24):2928-2934

7 Pijls NH, van Nunen LX. Fractional flow reserve, maximum hyperemia, adenosine, and regadenoson. Cardiovasc Revasc Med 2015;16(5):263-265

8 Adjedj J, Toth GG, Johnson NP, et al. Intracoronary adenosine: dose-response relationship with hyperemia. JACC Cardiovasc Interv 2015;8(11):1422-1430

9 Jang HJ, Koo BK, Lee HS, et al. Safety and efficacy of a novel hyperaemic agent, intracoronary nicorandil, for invasive physiological assessments in the cardiac catheterization laboratory. Eur Heart J 2013;34(27):2055-2062

10 Kato D, Takashima H, Waseda K, et al. Feasibility and safety of intracoronary nicorandil infusion as a novel hyperemic agent for fractional flow reserve measurements. Heart Vessels 2015;30(4):477-483 
11 Toth G, Hamilos M, Pyxaras S, et al. Evolving concepts of angiogram: fractional flow reserve discordances in 4000 coronary stenoses. Eur Heart J 2014;35(40):2831-2838

12 Sen S, Escaned J, Malik IS, et al. Development and validation of a new adenosine-independent index of stenosis severity from coronary wave-intensity analysis: results of the ADVISE (ADenosine Vasodilator Independent Stenosis Evaluation) study. J Am Coll Cardiol 2012;59(15):1392-1402

13 Escaned J, Echavarría-Pinto M, Garcia-Garcia HM, et al; ADVISE II Study Group. Prospective assessment of the diagnostic accuracy of instantaneous wave-free ratio to assess coronary stenosis relevance: results of ADVISE II international, multicenter study (ADenosine Vasodilator Independent Stenosis Evaluation II) JACC Cardiovasc Interv 2015;8(6):824-833

14 Jeremias A, Maehara A, Généreux P, et al. Multicenter core laboratory comparison of the instantaneous wave-free ratio and resting Pd/Pa with fractional flow reserve: the RESOLVE study. J Am Coll Cardiol 2014;63(13):1253-1261

15 Camici PG, Crea F. Coronary microvascular dysfunction. N Engl J Med 2007;356(8):830-840

16 van de Hoef TP, Bax M, Damman P, et al. Impaired coronary autoregulation is associated with long-term fatal events in patients with stable coronary artery disease. Circ Cardiovasc Interv 2013;6(4):329-335

17 van de Hoef TP, van Lavieren MA, Damman P, et al. Physiological basis and long-term clinical outcome of discordance between fractional flow reserve and coronary flow velocity reserve in coronary stenoses of intermediate severity. Circ Cardiovasc Interv 2014;7(3):301-311

18 Meuwissen M, Chamuleau SA, Siebes M, et al. The prognostic value of combined intracoronary pressure and blood flow velocity measurements after deferral of percutaneous coronary intervention. Catheter Cardiovasc Interv 2008;71(3):291-297

19 Yong AS, Ho M, Shah MG, Ng MK, Fearon WF. Coronary microcirculatory resistance is independent of epicardial stenosis. Circ Cardiovasc Interv 2012;5(1):103-108, S1-S2

20 Pijls NHJ, Van Gelder B, Van der Voort P, et al. Fractional flow reserve. A useful index to evaluate the influence of an epicardial coronary stenosis on myocardial blood flow. Circulation 1995;92(11):3183-3193

21 Coughlan JJ, MacDonnell C, Arnous S, Kiernan TJ. Fractional flow reserve in 2017: current data and everyday practice. Expert Rev Cardiovasc Ther 2017;15(6):457-472

22 Modi BN, van de Hoef TP, Piek JJ, Perera D. Physiological assessment of left main coronary artery disease. EuroIntervention 2017;13(7):820-827

23 Koo BK, Erglis A, Doh JH, et al. Diagnosis of ischemia-causing coronary stenoses by noninvasive fractional flow reserve computed from coronary computed tomographic angiograms. Results from the prospective multicenter DISCOVERFLOW (Diagnosis of Ischemia-Causing Stenoses Obtained Via Noninvasive Fractional Flow Reserve) study. J Am Coll Cardiol 2011;58(19):1989-1997

24 Min JK, Leipsic J, Pencina MJ, et al. Diagnostic accuracy of fractional flow reserve from anatomic CT angiography. JAMA 2012;308(12):1237-1245

25 Nørgaard BL, Leipsic J, Gaur S, et al; NXT Trial Study Group. Diagnostic performance of noninvasive fractional flow reserve derived from coronary computed tomography angiography in suspected coronary artery disease: the NXT trial (analysis of coronary blood flow using CT angiography: next steps) J Am Coll Cardiol 2014;63(12):1145-1155

26 Douglas PS, De Bruyne B, Pontone G, et al; PLATFORM Investigators. 1-Year outcomes of FFRCT-guided care in patients with suspected coronary disease: the PLATFORM study. J Am Coll Cardiol 2016;68(5):435-445
27 Pijls NH, van Schaardenburgh P, Manoharan G, et al. Percutaneous coronary intervention of functionally nonsignificant stenosis: 5-year follow-up of the DEFER study. J Am Coll Cardiol 2007;49(21):2105-2111

28 Tonino PAL, De Bruyne B, Pijls NH, et al; FAME Study Investigators. Fractional flow reserve versus angiography for guiding percutaneous coronary intervention. N Engl J Med 2009;360(3):213-224

29 De Bruyne B, Pijls NH, Kalesan B, et al; FAME 2 Trial Investigators. Fractional flow reserve-guided $\mathrm{PCI}$ versus medical therapy in stable coronary disease. N Engl J Med 2012;367(11):991-1001

30 Muller O, Mangiacapra F, Ntalianis A, et al. Long-term follow-up after fractional flow reserve-guided treatment strategy in patients with an isolated proximal left anterior descending coronary artery stenosis. JACC Cardiovasc Interv 2011;4(11):1175-1182

31 Li J, Elrashidi MY, Flammer AJ, et al. Long-term outcomes of fractional flow reserve-guided vs. angiography-guided percutaneous coronary intervention in contemporary practice. Eur Heart J 2013;34(18):1375-1383

32 Van Belle E, Rioufol G, Pouillot C, et al; Investigators of the Registre Français de la FFR-R3F. Outcome impact of coronary revascularization strategy reclassification with fractional flow reserve at time of diagnostic angiography: insights from a large French multicenter fractional flow reserve registry. Circulation 2014;129(2):173-185

33 Curzen N, Rana O, Nicholas Z, et al. Does routine pressure wire assessment influence management strategy at coronary angiography for diagnosis of chest pain?: the RIPCORD study. Circ Cardiovasc Interv 2014;7(2):248-255

34 Engstrøm T, Kelbæk H, Helqvist S, et al; DANAMI-3-PRIMULTI Investigators. Complete revascularisation versus treatment of the culprit lesion only in patients with ST-segment elevation myocardial infarction and multivessel disease (DANAMI-3PRIMULTI): an open-label, randomised controlled trial. Lancet 2015;386(9994):665-671

35 Smits P, Omerovic E, Abdel-Wahab M, et al. Two year results from the compare-acute trial. J Am Coll Cardiol 2018;71(S 11):1155-1273

36 Ahn JM, Park DW, Shin ES, et al; IRIS-FFR Investigatorst. Fractional flow reserve and cardiac events in coronary artery disease: data from a prospective IRIS-FFR Registry (Interventional Cardiology Research Incooperation Society Fractional Flow Reserve) Circulation 2017;135(23):2241-2251

37 Leone AM, Burzotta F, Aurigemma C, et al. Prospective randomized comparison of fractional flow reserve versus optical coherence tomography to guide revascularization of intermediate coronary stenoses: one-month results. J Am Heart Assoc 2019;8(15):e012772

38 Kuramitsu S, Matsuo H, Shinozaki T, et al; J-CONFIRM Registry Investigators. Two-year outcomes after deferral of revascularization based on fractional flow reserve: the J-CONFIRM Registry. Circ Cardiovasc Interv 2020;13(1):e008355

39 Van Belle E, Cosenza A, Baptista SB, et al; PRIME-FFR Study Group. Usefulness of routine fractional flow reserve for clinical management of coronary artery disease in patients with diabetes. JAMA Cardiol 2020;5(3):272-281

40 Fearon WF. Nonhyperemic coronary pressure ratios to assess percutaneous coronary intervention. JACC Cardiovasc Interv 2019;12(20):2015-2017

41 Davies JE, Sen S, Dehbi H-M, et al. Use of the instantaneous wave-free ratio or fractional flow reserve in PCI. N Engl J Med 2017;376(19):1824-1834

42 Götberg M, Christiansen EH, Gudmundsdottir IJ, et al; iFR-SWEDEHEART Investigators. Instantaneous wave-free ratio versus fractional flow reserve to guide PCI. N Engl J Med 2017;376(19):1813-1823 